\title{
A promoter SNP rs4073T $>$ A in the common allele of the interleukin 8 gene is associated with the development of idiopathic pulmonary fibrosis via the IL-8 protein enhancing mode
}

Mi-Hyun Ahn ${ }^{1+}$, Byung-Lae Park ${ }^{2+}$, Shin-Hwa Lee ${ }^{1}$, Sung-Woo Park', Jong-Sook Park', Do-Jin Kim', An-Soo Jang ${ }^{1}$, Jai-Soung Park ${ }^{3}$, Hwa-Kyun Shin ${ }^{4}$, Soo-Taek Uh', Yang-Ki Kim ${ }^{5}$, Young Whan Kim ${ }^{6}$, Sung Koo Han ${ }^{6}$, Ki-Suck Jung ${ }^{7}$, Kye Young Lee ${ }^{8}$, Sung Hwan Jeong ${ }^{9}$, Jeong Woong Park ${ }^{9}$, Byoung Whui Choi ${ }^{10}$, In Won Park ${ }^{10}$, Man Pyo Chung ${ }^{11}$, Hyoung Doo Shin ${ }^{2,12}$, Jin Woo Song ${ }^{13}$, Dong Soon Kim ${ }^{13^{*}}$, Choon-Sik Park ${ }^{1 *}$ and Young-Soo Shim ${ }^{6,14}$

\begin{abstract}
Background: Interleukin-8 (IL-8) is a potent chemo-attractant cytokine responsible for neutrophil infiltration in lungs with idiopathic pulmonary fibrosis (IPF). The IL-8 protein and mRNA expression are increased in the lung with IPF. We evaluated the effect of single nucleotide polymorphisms (SNPs) of the IL-8 gene on the risk of IPF.

Methods: One promoter (rs4073T>A) and two intronic SNPs (rs2227307T>G and rs2227306C>T) of the IL-8 genes were genotyped in 237 subjects with IPF and 456 normal controls. Logistic regression analysis was applied to evaluate the association of these SNPs with IPF. IL-8 in BAL fluids was measured using a quantitative sandwich enzyme immunoassay, and promoter activity was assessed using the luciferase reporter assay.

Results: The minor allele frequencies of rs4073T>A and rs2227307T>G were significantly lower in the 162 subjects with surgical biopsy-proven IPF and 75 subjects with clinical IPF compared with normal controls in the recessive model $(\mathrm{OR}=0.46$ and $0.48, p=0.006$ and 0.007 , respectively). The IL-8 protein concentration in BAL fluids significantly increased in 24 subjects with IPF compared with 14 controls $(p=0.009)$. Nine IPF subjects homozygous for the rs4073 T>A common allele exhibited higher levels of the IL-8 protein compared with six subjects homozygous for the minor allele $(p=0.024)$. The luciferase activity of the rs4073T>A common allele was significantly higher than that of the rs4073T>A minor allele $(p=0.002)$.
\end{abstract}

Conclusion: The common allele of a promoter SNP, rs4073T>A, may increase susceptibility to the development of IPF via up-regulation of IL-8.

\section{Introduction}

Idiopathic pulmonary fibrosis (IPF) is a devastating disease of the idiopathic interstitial pneumonia family. It predominantly affects the lung parenchyma and is characterized by progressive dyspnea and worsening lung

\footnotetext{
*Correspondence: dskim@amc.seoul.kr; mdcspark@unitel.co.kr + Contributed equally

'Div. of Allergy and Respiratory Medicine, Dept. of Internal Medicine, Soonchunhyang Univ. Bucheon Hospital, 1174, Jung-dong, Wonmi-gu, Bucheon, 420-020, Korea

${ }^{13}$ Div. of Pulmonary and Critical Care Medicine, Asan Medical Center, Univ. of Ulsan, Asanbyungwon-gil, Songpa-gu, Seoul, 138-736, Korea Full list of author information is available at the end of the article
}

function [1]. Although the pathogenesis of IPF is largely unknown, a current hypothesis suggests aberrant wound healing of ongoing alveolar epithelial injury and repair associated with the formation of patchy fibroblast-myofibroblast foci, which evolve to fibrosis [2,3]. The processes of inflammation and fibrosis likely involve an interaction between environmental triggers and genetic background [2]. Supporting evidence for the genetic background for pulmonary fibrosis is the familial occurrence, as seen in familial IPF [4]. However, the nature of the genetic basis for sporadic IPF has not been evaluated due to low disease incidence. Recent reports suggest 
that genetic polymorphisms of putative candidate genes contribute to the development of lung fibrosis [5-7].

Characteristic of IPF is neutrophilia of the bronchoalveolar lavage fluid. The recruitment and activation of neutrophils plays a fundamental role in the development of lung injury, which precedes aberrant wound repair in the pathogenesis of IPF[3]. Interleukin-8 (IL-8) acts as a potent chemoattractant for neutrophils [8]. The IL-8 protein and mRNA expression are increased in the BAL fluid and the alveolar macrophages of patients with IPF [9]. An animal study also confirmed the role of IL-8 in pulmonary fibrosis by demonstrating that bleomycininduced lung fibrosis is attenuated by the neutralization of IL-8[10]. In addition to promoting inflammation, IL-8 has angiogenic activity[11,12]. Thus, genetic alterations of IL- 8 may be related to the development of IPF.

In humans, the gene encoding IL- 8 is located on chromosome 4q12-q21 and consists of four exons and three introns [13]. Polymorphisms of IL-8 are associated increased risk of developing various cancers [14]. SNPs within IL8 have been reported as candidates for cystic fibrosis lung disease, a neutrophil-dominant inflammatory lung disease like IPF [15]. Although a previous study reported no association between IPF risk and these SNPs [16], the study had a small sample size of 71 patients with IPF including 31 surgical biopsy-proven cases. Thus, a study with a relatively large sample size was needed to examine the genetic effect of polymorphisms of the IL- 8 gene on the risk of IPF. We genotyped and compared the frequencies of three SNPs of the IL-8 genes in 237 subjects with IPF and 456 normal controls and evaluated their association with the development of IPF, as well as performed functional validation.

\section{Methods}

\section{Study subjects}

Subjects with IPF were recruited from the Korean Cohort of Interstitial Lung Disease. The study population comprised 237 patients with IPF recruited from January 1984 to November 2004 from eight university hospitals. Normal (control) subjects $(n=456)$ were the spouses of the patients or volunteers from the general population. Control subjects were at least 50 years old, had no respiratory symptoms, exhibited normal FVC and FEV1 ( $>75 \%$ of the predicted value), and normal findings on a simple chest posterior-anterior view $\mathrm{x}$-ray. The diagnosis of IPF was based on an international consensus statement by ATS/ERS with compatible findings via surgical lung biopsy $(n=162)$ or using radio-clinical criteria $(n=75)$, i.e., the presence of clinical, functional, and high-resolution computed tomography patterns strongly consistent with IPF. None of the patients with IPF had any evidence of the underlying collagen vascular diseases clinically or by laboratory diagnosis. The institutional review board by Soonchunhyang University hospital for human studies approved the protocol, and informed written consent was obtained from all subjects.

\section{Genotyping with fluorescence polarization detection}

To genotype polymorphic sites, primers and probes were designed for TaqMan ${ }^{\circledR}$ 17. Primer Express (Applied Biosystems, Foster, CA, USA) was used to design both the PCR primers and the MGB TaqMan probes. One allelic probe was labeled with the FAM dye and the other was labeled with fluorescent VIC dye. The PCRs were run on the TaqMan Universal Master mix without UNG (Applied Biosystems), with a PCR primer concentration of $900 \mathrm{nM}$ and a TaqMan MGB-probe concentration of $200 \mathrm{nM}$. The reactions were carried out in a 384-well format in a total reaction volume of 50 ul using $20 \mathrm{ng}$ of the genomic DNA. The plates then were placed in a thermal cycler (PE 9700, Applied Biosystems) and heated to $50^{\circ} \mathrm{C}$ for $2 \mathrm{~min}$ and $95^{\circ} \mathrm{C}$ for 10 min followed by 40 cycles of $95^{\circ} \mathrm{C}$ for $15 \mathrm{sec}$ and $60^{\circ} \mathrm{C}$ for $1 \mathrm{~min}$. The TaqMan assay plates were then transferred to a Prism 7900HT instrument (Applied Biosystems), which measured the fluorescence intensity in each well of the plate. The fluorescence data files from each plate were analyzed using automated software (SDS 2.1). Detailed information concerning the primers is presented in additional file 1 , table $\mathrm{S} 1$.

Bronchoalveolar lavage and enzyme immunoassay of IL-8 BAL had been performed in the most affected lobe by computed tomography in the 24 subjects without any immunosuppressive therapy and in the right middle lobe of 14 normal controls, as described previously[17]. The supernatant was separated from cell pellets by centrifugation at $500 \times g$ for 5 minutes. IL- 8 in BAL fluids was measured using a quantitative sandwich enzyme immunoassay kit (BD Pharmingen, San Diego, CA, USA). The lower limit of detection for IL-8 was 15.6 $\mathrm{pg} / \mathrm{mL}$. Values below this limit were assumed to be 0 $\mathrm{pg} / \mathrm{mL}$ for the statistical analysis. The inter- and intraassay coefficients of variance were below $10 \%$. Protein concentration of BAL samples was measured for standardization using a micro BCA protein assay kit (Pierce, Rockford, IL, USA).

\section{Assessing promoter activity using the luciferase reporter assay}

The promoter region of IL-8 was amplified using PCR. The genomic DNA fragment was isolated from B cell lines of the IPF subjects using a genomic DNA preparation kit (Gentra, Ipswich, MA, USA). The first PCR product was amplified using the following primers: forward; 5'-TGCCTTTGGAAGATTCTGCT-3', reverse; 5'GCCAGCTTGGAAGTCATGTT-3'. The primary PCR 
reaction mixture was diluted and used as a template for a nested PCR reaction using the nested primers containing restriction enzyme sequences (forward; 5'-ACTGGTACC (KpnI)ACATTACTCAGAAA-3', reverse; 5'CCTACGCGT(MluI)GTCTCTGAAAGTTTG-3’) for construction of the IL8 reporter plasmid. The amplified fragment of the promoter region of the IL8 gene (-79 to $-743 \mathrm{bp}$ from the transcription start site) was cloned using the pGEM-T easy vector system (Promega Co. Madison, WI, USA), was ligated with pGL-3 basic Luc+ reporter vector (Promega). Cloned DNA sequences were determined by a DNA direct-sequencing service (Genotech, Daejeon, Korea). One day before transfection, 293 $\mathrm{T}$ cells were seeded at $5 \times 10^{5}$ cells per well (6-well plate) in $2 \mathrm{ml}$ with $10 \% \mathrm{FBS}$. A $2-\mu \mathrm{g}$ aliquot of the IL8pGL3 basic constructor plasmid and $50 \mathrm{ng}$ of PSVgalactosidase reporter vector (Promega, transfection parameter) were diluted in $250 \mu \mathrm{l}$ OptMEM (GIBCO $\mathrm{BRL}$, Burlington, MD, USA) without serum. The $4 \mu \mathrm{l}$ of lipofectamine 2000 (recommended DNA ug: lipofectamine $\mathrm{ul}=1: 2$, Invitrogen, Carlsbad, CA) was diluted in 250 ul OptMEM (GIBCO BRL) per well. The diluted DNA was combined with the diluted lipid (total volume $500 \mu \mathrm{l}$ per well). Then, $500 \mu \mathrm{l}$ of transfection complex was added, and the cells were incubated at $37^{\circ} \mathrm{C}$ with $5 \% \mathrm{CO} 2$ in humidified air for $48 \mathrm{~h}$. $\beta$-galactosidase activity was measured by ortho-nitrophenyl-D-galactopyranoside (ONPG) hydrolysis using $\beta$-Gal Assay kit (Promega). The cells were solubilized by scraping with $400 \mu \mathrm{l}$ of cell lysis buffer of Luciferase Assay System kit (Promega). Luciferase activity was measured using the Luciferase Assay System and luminometer (VICTOR3, Perkinelmer, Waltham, MA, USA). And the relative luciferase activity was normalized to the protein concentration and $\beta$-galactosidase activity.

\section{Statistics}

We applied widely used measures of linkage disequilibrium to all pairs of biallelic loci: Lewontin's D' (|D'|) [18] and $r^{2}$. Haplotypes of each individual were inferred using the PHASE algorithm (ver. 2.0) developed by Stephens et al. [19]. The genotype and haplotype distributions were analyzed using logistic regression models with age (continuous value), gender (male $=0$, female $=$ 1 ), smoking status (non-smoker $=0$, ex-smoker $=1$, smoker $=2$ ), atopy (absence $=0$, presence $=1$ ), and BMI as covariates. Cox models were used for calculating relative hazards and $\mathrm{P}$-values controlling age, sex and smoking status[20]. Mantel-Haenszel chi-square (MHC) tests were used to test for trend in the categorical analysis. The data were managed and analyzed using SAS version 9.1 (SAS Inc., Cary, NC, USA). Statistical power of single associations was calculated with false-positive rate of $5 \%$ and four given MAFs and sample sizes and assuming a relative risk of 1.5, using PGA (Power for Genetic Association Analyses) software [21].

\section{Results}

\section{Clinical profiles of study subjects}

Clinical profiles of the study subjects are summarized in Table 1 . In total, 237 subjects with IPF and 456 normal controls were recruited. Age and sex ratios of normal controls were similar to those of the subjects with IPF. The 162 subjects with biopsy-proven IPF and the 75 subjects with clinical IPF had similar age and sex ratios. The frequency of current smokers and ex-smokers were higher in the subjects with both biopsy-proven IPF and clinical IPF compared with that in normal controls. The patients with IPF had a significant reduction in FVC when compared with normal control subjects $(p<0.01)$. The subjects with biopsy-proven IPF and those with clinical IPF had the comparable impairment of FVC and DLCO.

\section{Association of SNPs within the IL8 gene with development of IPF}

One promoter SNP (rs4073T $>$ A) and two intronic SNPs ( $r 2227307 \mathrm{~T}>\mathrm{G}$ and $\mathrm{rs} 2227306 \mathrm{C}>\mathrm{T})$ within the IL8 gene were genotyped in IPF patients and normal subjects (see Additional file 2, figure S1). Frequencies and heterozygosities of the SNPs are presented in additional file 3, table S2. Genotype distributions of the SNPs were in Hardy-Weinberg equilibrium $(p<0.05)$. The LDs were calculated, and haplotypes of IL8 polymorphisms were constructed (see Additional file 2, figure S1 B and C). Three major haplotypes with over $5 \%$ of MAF were detected. However, IL8-ht1 and IL8-ht2 were not analyzed due to their equivalency with IL8 rs4073 and L8 rs2227306, respectively. IL8 rs4073 and rs2227307 were significantly associated with a decreased risk of developing IPF and clinical IPF in the recessive model $(\mathrm{OR}=$ 0.46 and $\mathrm{OR}=0.48, p=0.006$ and $p=0.007$, respectively; Table 2). The minor allele frequencies of

Table 1 Clinical profiles of study subjects

\begin{tabular}{llll}
\hline Description & $\begin{array}{l}\text { Normal } \\
\text { controls }\end{array}$ & IPF & Clinical-IPF \\
\hline $\mathrm{N}$ & 456 & 162 & 75 \\
Age, yr (range) & $62(50-87)$ & $58(41-83)$ & $66(47-83)$ \\
Sex (male/female) & $278 / 178$ & $112 / 50$ & $51 / 24$ \\
Current Smoker (\%)/Ex- & $13.8 / 14.4$ & $28.4 / 30.2$ & $24.0 / 28.0$ \\
smoker (\%) & & & \\
FVC \% pred. & $98.70 \pm 16.73$ & $72.56 \pm 17.37$ & $70.94 \pm 17.28$ \\
DLCO \% pred. & ND & $66.60 \pm 19.51$ & $60.71 \pm 22.05$ \\
\hline
\end{tabular}

IPF: Idiopathic pulmonary fibrosis

FVC: forced expiratory vital capacity

DLCO: Carbon Monoxide Diffusing Capacity

pred.: prediction

ND: not determined 
Table 2 The association of IL8 SNPs with the risk of idiopathic pulmonary fibrosis (IPF)

\begin{tabular}{|c|c|c|c|c|c|c|c|c|c|c|c|c|c|c|c|}
\hline \multirow[t]{2}{*}{ rs } & \multirow[t]{2}{*}{ s } & \multicolumn{2}{|c|}{ Distribution } & \multicolumn{3}{|c|}{ Codominant } & \multicolumn{3}{|c|}{ Dominant } & \multicolumn{3}{|c|}{ Recessive } & \multicolumn{2}{|c|}{ MAF } & \multirow{2}{*}{$\begin{array}{c}\text { Statistica } \\
\text { power }\end{array}$} \\
\hline & & Case & $\mathrm{NC}$ & OR(95\%Cl) & $P$ & Pcorr & $\begin{array}{c}\text { OR(95\% } \\
\text { Cl) }\end{array}$ & $P$ & Pcorr & $\begin{array}{c}\text { OR(95\% } \\
\text { Cl) }\end{array}$ & $P$ & Pcorr & Case & NC & \\
\hline \multirow[t]{3}{*}{ rs4073 } & $\bar{T}$ & $\begin{array}{c}87 \\
(41.63 \%)\end{array}$ & $\begin{array}{c}191 \\
(42.16 \%)\end{array}$ & & & & & & & & & & & & \\
\hline & AT & $\begin{array}{c}103 \\
(49.28 \%)\end{array}$ & $\begin{array}{c}191 \\
(42.16 \%)\end{array}$ & $\begin{array}{c}0.84(0.65- \\
1.08)\end{array}$ & 0.17 & 0.22 & $\begin{array}{c}1.00(0.71 \\
-1.42)\end{array}$ & 0.99 & 1 & $\begin{array}{c}0.46 \\
(0.26- \\
0.80)\end{array}$ & 0.006 & 0.008 & 0.337 & 0.368 & $82.2 \%$ \\
\hline & A & 19(9.09\%) & $\begin{array}{c}71 \\
(15.67 \%)\end{array}$ & & & & & & & & & & & & \\
\hline \multirow[t]{3}{*}{ rs2227307 } & $\mathrm{T}$ & $\begin{array}{c}94 \\
(42.34 \%)\end{array}$ & $\begin{array}{c}191 \\
(42.35 \%)\end{array}$ & & & & & & & & & & & & \\
\hline & GT & $\begin{array}{c}107 \\
(48.20 \%)\end{array}$ & $\begin{array}{c}189 \\
(41.91 \%)\end{array}$ & $\begin{array}{c}0.83(0.65- \\
1.06)\end{array}$ & 0.14 & 0.19 & $\begin{array}{c}0.97(0.69 \\
-1.37)\end{array}$ & 0.87 & 1 & $\begin{array}{c}0.48 \\
(0.28- \\
0.82)\end{array}$ & 0.007 & 0.009 & 0.336 & 0.367 & $93.5 \%$ \\
\hline & G & $21(9.46 \%)$ & $\begin{array}{c}71 \\
(15.74 \%)\end{array}$ & & & & & & & & & & & & \\
\hline \multirow[t]{3}{*}{ rs2227306 } & C & $\begin{array}{c}103 \\
(48.13 \%)\end{array}$ & $\begin{array}{c}216 \\
(47.58 \%)\end{array}$ & & & & & & & & & & & & \\
\hline & CT & $\begin{array}{c}95 \\
(44.39 \%)\end{array}$ & $\begin{array}{c}196 \\
(43.17 \%)\end{array}$ & $\begin{array}{c}0.92(0.70- \\
1.19)\end{array}$ & 0.51 & 0.67 & $\begin{array}{c}0.97(0.69 \\
-1.36)\end{array}$ & 0.84 & 1 & $\begin{array}{c}0.70(0.37- \\
1.30)\end{array}$ & 0.26 & 0.34 & 0.297 & 0.308 & $79.9 \%$ \\
\hline & $\mathrm{T}$ & $16(7.48 \%)$ & $42(9.25 \%)$ & & & & & & & & & & & & \\
\hline \multirow[t]{3}{*}{ IL8_ht3 } & $-/$ & $\begin{array}{c}175 \\
(91.15 \%)\end{array}$ & $\begin{array}{c}398 \\
(87.86 \%)\end{array}$ & & & & & & & & & & & & \\
\hline & ht3/- & $16(8.33 \%)$ & $\begin{array}{c}55 \\
(12.14 \%)\end{array}$ & $\begin{array}{c}0.65(0.37- \\
1.16)\end{array}$ & 0.15 & 0.19 & $\begin{array}{c}0.61(0.34 \\
-1.10)\end{array}$ & 0.10 & 0.13 & & . & & 0.047 & 0.061 & $35.6 \%$ \\
\hline & $\begin{array}{l}\text { ht3/ } \\
\text { ht3 }\end{array}$ & $1(0.52 \%)$ & $0(0.00 \%)$ & & & & & & & & & & & & \\
\hline
\end{tabular}

* Logistic models were used for calculating odd ration and p-values in recessive model controlling for age, sex, and smoking status as covariates.

NC: normal controls

MAF: Minor allele frequency

rs4073T $>$ A and $\mathrm{rs} 2227307 \mathrm{~T}>\mathrm{G}$ were significantly lower in the subjects with IPF compared with that in normal controls (33.7\% vs. $36.8 \%$ and $33.6 \%$ and $36.7 \%$, respectively). When the study subjects were stratified by gender, the association of the two SNPs was restricted to male gender (Table 3).

Association of rs4073T>A within the IL-8 gene with IL-8 protein levels in BAL fluids

The amount of IL- 8 protein was measured in BAL fluids from 24 subjects with IPF and 14 NC. IL-8 concentrations were significantly increased in IPF patients compared with $\mathrm{NC}(9.24 \pm 1.11 \mathrm{pg} / \mathrm{mg}$ of protein vs. $1.71 \pm 0.27 \mathrm{pg} / \mathrm{mg}$ of protein, $p=0.009$, Figure 1). A total of 15 subjects with IPF were genotyped, and the subjects with IPF exhibiting $\mathrm{rs4073T}>\mathrm{A}$, a common allele homozygote, had a higher level of IL- 8 protein $(27.01 \pm 3.45 \mathrm{pg} / \mathrm{mg}$ of protein $)$ than of minor allele homozygotes $(2.35 \pm 0.46 \mathrm{pg} / \mathrm{mg}$ of protein, $p=0.024)$. The IL- 8 concentration in BAL fluids did not differ among individuals with the $\mathrm{rs} 2227307 \mathrm{~T}>\mathrm{G}$ genotype (data, not shown).

Table 3 The association of IL8 SNPs with the risk of idiopathic pulmonary fibrosis (IPF) by gender

\begin{tabular}{|c|c|c|c|c|c|c|c|}
\hline Male & & & & Female & & & \\
\hline MAF & & OR $(95 \% \mathrm{Cl})^{*}$ & $\mathrm{P}^{*}$ & MAF & & OR $(95 \% \mathrm{Cl})^{*}$ & $\mathrm{P}^{*}$ \\
\hline IPF and Clinical IPF $(n=152)$ & $N C(n=178)$ & & & IPF and Clinical IPF $(n=70)$ & $N C(n=276)$ & & \\
\hline 0.340 & 0.394 & $0.51(0.26-0.97)$ & 0.04 & 0.331 & 0.351 & $0.53(0.18-1.57)$ & 0.25 \\
\hline 0.336 & 0.394 & $0.49(0.26-0.93)$ & 0.03 & 0.336 & 0.350 & $0.57(0.20-1.64)$ & 0.30 \\
\hline 0.288 & 0.326 & $0.83(0.39-1.75)$ & 0.62 & 0.316 & 0.297 & $0.64(0.19-2.24)$ & 0.49 \\
\hline 0.064 & 0.071 & & . & 0.008 & 0.054 & & \\
\hline
\end{tabular}

* Logistic models were used for calculating odd ration and p-values in recessive model controlling for age, sex, and smoking status as covariates. NC: normal controls 


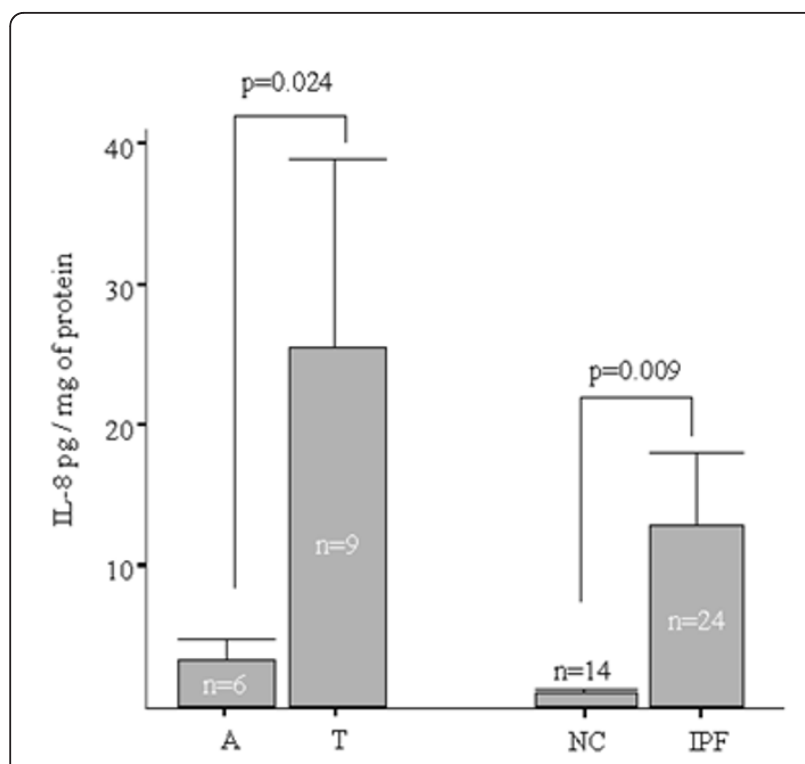

Figure 1 Levels of IL-8 protein of in BAL fluid collected from normal controls and subjects with IPF. NC: normal controls, IPF: Surgical IPF, A: IPF subjects having rs4073 $\Pi$ alleles, T: IPF subjects having rs4073 AA alleles. Levels of IL-8 protein were normalized with BAL protein concentration.

\section{Comparison of promoter activity between $T T$ and $A A$ alleles of the IL8 promoter rs4073T $>$ A}

Given that the $\operatorname{rs} 4073 T>A$ is located in the promoter region, we investigated the promoter activity of rs4073T $>A$ using luciferase reporter assay. The luciferase activity was adjusted by pGL3 basic vector, and the yield of DNA transfection adjusted using pSV-b-galactosidase (+) vector and ONPG activity. The luciferase activity of the $\operatorname{rs} 4073 T>A T T$ allele was significantly higher than that of the rs4073T $>A A A$ allele $(25.2 \pm 2.8$ vs. $6.8 \pm 0.7, p=0.002$, Figure 2).

\section{Discussion}

Our logistic regression analysis of a case-control study determined that the IL8 $\mathrm{rs4073T}>A$ and $\mathrm{rs} 2227307 \mathrm{~T}>\mathrm{G}$ SNPs from the promoter region are associated with development of IPF. The frequencies of the minor allele of the two SNPs were significantly decreased in IPF subjects compared with normal controls. These are the first data to indicate that the common alleles may increase susceptibility to development of IPF. Several reports have shown a relationship between IL8 gene polymorphisms and human lung diseases [22-26]. Two SNPs in the IL8 genes (rs4073 and rs2227307) were evaluated in patients with systemic sclerosis with $(\mathrm{n}=78)$ or without fibrosing alveolitis $(n=50)$, those with cryptogenic fibrosing alveolitis $(\mathrm{n}=71)$, and normal healthy subjects in the UK [16]. These study reported no association of the SNPs of IL8 with the risk of pulmonary fibrosis. The

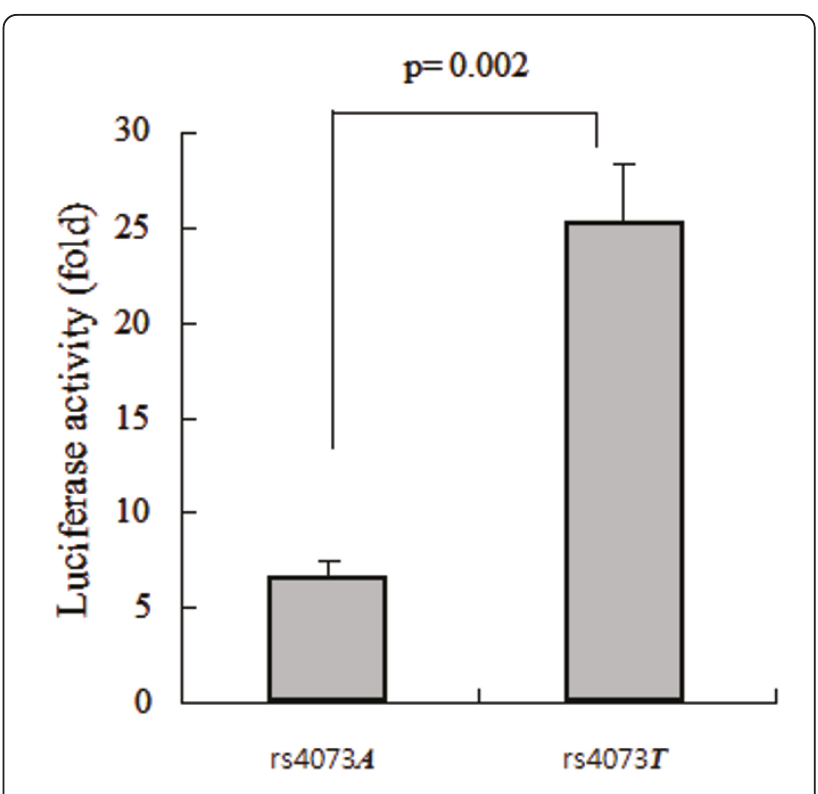

Figure 2 Comparison of luciferase activity between rs40730TT and rs40703AA alleles. The luciferase activity adjusted by pGL3 basic vector and the yield of DNA transfection adjusted using pSVb-galactosidase (+) vector and ONPG activity.

discrepancy between ours and the previously reported results may be due to the small study population in the previous study[16] or to ethnicity differences between study cohorts, as the minor allele frequency of rs $4073 \mathrm{~T}>\mathrm{A}$ was $33.7 \%$ in our study subjects with IPF, whereas it was $56 \%$ in the UK study. Interestingly, the rs4073T $>$ A polymorphism has recently been reported to be a risk factor of other lung diseases, including bronchial asthma [23] and bronchiolitis, caused by respiratory syncytial virus [22,24]. In addition, Hillian AD and coworkers reported an association of the rs $4073 \mathrm{~T}>\mathrm{A}$ and cystic fibrosis when the analysis was restricted to male subjects. In the present study, the SNP was also significantly associated with IPF restricted to male gender[15]. This data suggest that the SNP may have a genetics effect on IL-8 gene expression in male gender, but not in female gender. We could not explain the restriction of the SNP to male gender. The location of IL-8 is in chromosome 4q13-q21, and the transcription factor supposed to bind to the SNP: eEF1A1 is in chromosome 6q14.1. Plasma IL-8 levels were reported to be similar in the subjects with male or female gender following sever trauma [15]. Further study on the association restricted to male would be performed.

We did not validate the association between the SNPs of the IL-8 gene in an independent replication population. We evaluate the effect of the SNP on IL-8 gene or protein expression instead. We measured IL-8 protein concentrations in the lung. IL- 8 protein was increased in the BAL 
fluids of patients with IPF compared with normal controls. The IL- 8 protein level in BAL fluid was significantly increased in the subjects with IPF having the common allele of $\operatorname{rs} 4073 \mathrm{~T}>A$ compared to those with the minor allele. This result indicates that the $\mathrm{rs4073T}>A$ allele within the promoter may result in increased IL- 8 production when compared with the minor allele.

The promoter activity was examined using a luciferase reporter vector, and the promoter activity of the rs4073T $>A T T$ allele was significantly stronger than that of the rs4073T $>A A A$ allele. This is in accordance with a previous study, which reported that the $\operatorname{rs} 4073 T>A T T$ allele exhibited 2- to 5-fold stronger transcriptional activity than did the $\operatorname{rs} 4073 T>A A A$ counterpart [27]. Given that high IL-8 concentrations in BAL fluid were associated with the common allele of rs4073 $\mathrm{T}>\mathrm{A}$ in the present study, our luciferase data confirm that the rs4073 $T$ allele on the promoter may enhance the IL-8 transcription compared with the rs4073 A allele. Putative transcription factor binding sites in the promoter of the IL8 gene were searched using the TFSEARCH and TESS websites. The candidate binding protein for the transcription of IL8 at rs4073 was eEF1A1 (see Additional file 4, figure S2). The eEF1A family consists of two members, eEF1A1 and eEF1A2 [28]. Thus, eEF1A1 may regulate the activation and production of IL- 8 as a transcription enhancer or inducer; this is a topic for future research.

In summary, we evaluated the genetic effect of IL-8 gene polymorphisms on the risk of IPF using a relatively large size population of subjects with IPF and normal controls. Logistic regression analysis demonstrated that the minor allele frequencies of $\mathrm{rs4073T}>\mathrm{A}$ was significantly lower in the subjects with IPF compared with that in normal controls. The subjects with IPF homozygous for the rs4073T>A common allele exhibited significantly higher IL- 8 protein concentrations in BAL fluids and enhanced luciferase activities compared with those homozygous for the rare allele. This study shows that the IL8 rs4073 T allele is significantly associated with an increased risk of IPF in the Korean population and this effect may result from the up-regulation of IL-8 protein synthesis in the lung. Our results may provide the clue of the genetic contribution to the pathogenesis of IPF.

\section{Additional material}

Additional file 1: The fluorescence labeled allelic probe for amplification of IL8, IL8RA and IL8RB genes. The data provided represent the probe for amplification of IL8, IL8RA and IL8RB genes. Additional file 2: SNPs on the map of the IL8 gene, linkage disequilibrium, and haplotypes of IL8 genes. The figure provided represent the map of the IL8 gene, linkage disequilibrium, and haplotypes of IL8 genes.
Additional file 3: The Minor allele frequency (MAF), Heterozygosity, Hardy-Weinberg equilibrium (HWE) of IL8 gene polymorphisms. The data provided represent the MAF, HWE of IL8 gene polymorphisms.

Additional file 4: The candidate binding protein for the transcription of IL8 at rs4073. The figure provided represent the putative transcription factor binding sites in the promoter of the IL8 gene.

\section{Abbreviations list}

(IPF): Idiopathic pulmonary fibrosis; (IL-8): Interleukin-8; (ONPG): orthonitrophenyl-D-galactopyranoside; (|D'|): Lewontin's D'; (MHC): MantelHaenszel chi-square:

\section{Acknowledgements}

Declaration of all sources of funding: This study was supported by a grant from the Korea Healthcare Technology R\&D Project, Ministry for Health, Welfare, and Family Affairs, Republic of Korea (A090548). BAL samples were generously provided by a Collaborative Biobank of Korea in Soonchunhyang University Bucheon Hospital.

Korea Genetic Study Group for Interstitial Lung Diseases;

Soonchunhyang Univ. Hosp.; Seoul National Univ. Hosp.; Hallym Univ. Hosp.; Dankook Univ. Hosp.; Kachun Univ.

Gil Hosp.; Chung-Ang Univ. Hosp.; Sungkyunkwan Univ.; Asan Medical Center-Ulsan Univ.; SNP Genetics, Inc.

\section{Author details}

${ }^{1}$ Div. of Allergy and Respiratory Medicine, Dept. of Internal Medicine, Soonchunhyang Univ. Bucheon Hospital, 1174, Jung-dong, Wonmi-gu, Bucheon, 420-020, Korea. Dept. of Genetic Epidemiology, SNP-Genetics Inc., B-1407, WooLim Lion's Valley, 371-28 Gasan-Dong, Geumcheon-Ku, Seoul, 153-803, Korea. 'Div. of Radiology, Soonchunhyang Univ. Bucheon Hosp., 1174, Jung-Dong, Wonmi-Gu, Bucheon, Gyeonggi-Do, 420-020, Korea. ${ }^{4}$ Div. of Thoracic and Cardiovascular Surgery, Soonchunhyang Univ. Bucheon Hosp., 1174, Jung-Dong, Wonmi-Gu, Bucheon, Gyeonggi-Do, 420-020, Korea. ${ }^{5}$ Div. of Allergy and Respiratory Medicine, Soonchunhyang Univ. Seoul Hosp. 657-58, Hannam-dong, Yongsan-gu, Seoul, 140-743, Korea. ${ }^{6}$ Dept. of Internal Medicine, Seoul National Univ. Hosp., 28 Yongon-dong, Seoul, Korea. ${ }^{7}$ Dept. of Respiratory and Critical Care Medicine, Hallym Univ., Korea. ${ }^{8}$ Dept. of Internal Medicine, College of Medicine, Dankook Univ., Cheonan, Korea. ${ }^{9}$ Div. of Pulmonary Medicine, Dept. of Internal Medicine, Gachon Medical School Gil Medical Center, Korea. ${ }^{10}$ Department of Internal Medicine, Chung Ang University College of Medicine, Seoul, Korea. ${ }^{11}$ Div. of Pulmonary and Critical Care Medicine, Samsung Medical Center, Sungkyunkwan Univ. School of Medicine, Seoul, Korea. ${ }^{12}$ Dept. of Life Science, Sogang Univ., Sinsu-dong, Mapo-gu, Seoul, 121-742, Korea. ${ }^{13}$ Div. of Pulmonary and Critical Care Medicine, Asan Medical Center, Univ. of Ulsan, Asanbyungwon-gil, Songpagu, Seoul, 138-736, Korea. ${ }^{14}$ Dept. of Medicine, Armed Force Capital Hospital, Bundang-gu, Seongnam-si, Kyonggi-do, Korea.

\section{Authors' contributions}

MHA performed all experimental steps; BLP, SHL, and HDS analyzed statistics and wrote the manuscript; SWP, JSP, DJK and ASJ provided experimental assistance; JSP, HKS, SU, YK, YWK, SKH, KSJ, KYL, SHJ, JWP, BWC, IWP, MPC, JWS, DSK and YSS supervised this project; CSP conceptualized of the study and wrote the first draft of the manuscript. All authors read and approved the final manuscript.

The authors thank the editors from textcheck.com, both native speakers of English, for their proofreading for grammar and typographic errors. For a certificate, see http://www.textcheck.com/certificate/ox3Vhg.

\section{Competing interests}

The authors declare that they have no competing interests.

Received: 13 January 2011 Accepted: 8 June 2011

Published: 8 June 2011 


\section{References}

1. American Thoracic Society: Idiopathic pulmonary fibrosis: diagnosis and treatment. International consensus statement. American Thoracic Society (ATS), and the European Respiratory Society (ERS). Am J Respir Crit Care Med 2000, 161(2 Pt 1):646-664

2. Gross TJ, Hunninghake GW: Idiopathic pulmonary fibrosis. N Engl J Med 2001, 345(7):517-525.

3. Selman M, King TE, Pardo A: Idiopathic pulmonary fibrosis: prevailing and evolving hypotheses about its pathogenesis and implications for therapy. Ann Intern Med 2001, 134(2):136-151.

4. Marshall RP, Puddicombe A, Cookson WO, Laurent GJ: Adult familial cryptogenic fibrosing alveolitis in the United Kingdom. Thorax 2000, 55(2):143-146.

5. Bremer LA, Blackman SM, Vanscoy LL, McDougal KE, Bowers A, Naughton KM, Cutler DJ, Cutting GR: Interaction between a novel TGFB1 haplotype and CFTR genotype is associated with improved lung function in cystic fibrosis. Hum Mol Genet 2008, 17(14):2228-2237.

6. Grutters JC, du Bois RM: Genetics of fibrosing lung diseases. Eur Respir J 2005, 25(5):915-927.

7. Vasakova M, Striz I, Slavcev A, Jandova S, Kolesar L, Sulc J: Th1/Th2 cytokine gene polymorphisms in patients with idiopathic pulmonary fibrosis. Tissue Antigens 2006, 67(3):229-232.

8. Oppenheim JJ, Zachariae CO, Mukaida N, Matsushima K: Properties of the novel proinflammatory supergene "intercrine" cytokine family. Annu Rev Immunol 1991, 9:617-648.

9. Southcott AM, Jones KP, Li D, Majumdar S, Cambrey AD, Pantelidis P, Black CM, Laurent GJ, Davies BH, Jeffery PK: Interleukin-8. Differential expression in lone fibrosing alveolitis and systemic sclerosis. Am J Respir Crit Care Med 1995, 151(5):1604-1612.

10. Keane MP, Belperio JA, Moore TA, Moore BB, Arenberg DA, Smith RE, Burdick MD, Kunkel SL, Strieter RM: Neutralization of the CXC chemokine, macrophage inflammatory protein-2, attenuates bleomycin-induced pulmonary fibrosis. J Immunol 1999, 162(9):5511-5518.

11. Ebina M, Shimizukawa M, Shibata $N$, Kimura $Y$, Suzuki T, Endo M, Sasano $H$, Kondo T, Nukiwa T: Heterogeneous increase in CD34-positive alveolar capillaries in idiopathic pulmonary fibrosis. Am J Respir Crit Care Med 2004, 169(11):1203-1208.

12. Keane MP, Arenberg DA, Lynch JP, Whyte RI, lannettoni MD, Burdick MD, Wilke CA, Morris SB, Glass MC, DiGiovine B, Kunkel SL, Strieter RM: The CXC chemokines, IL- 8 and IP-10, regulate angiogenic activity in idiopathic pulmonary fibrosis. J Immunol 1997, 159(3):1437-1443.

13. Mukaida N, Shiroo M, Matsushima K: Genomic structure of the human monocyte-derived neutrophil chemotactic factor IL-8. J Immunol 1989, 143(4):1366-1371.

14. Arinir U Klein W, Rohde G, Stemmler S, Epplen JT, Schultze-Werninghaus G: Polymorphisms in the interleukin- 8 gene in patients with chronic obstructive pulmonary disease. Electrophoresis 2005, 26(15):2888-2891.

15. Hillian AD, Londono D, Dunn JM, Goddard KA, Pace RG, Knowles MR, Drumm ML: Modulation of cystic fibrosis lung disease by variants in interleukin-8. Genes Immun 2008, 9(6):501-508.

16. Renzoni E, Lympany $P$, Sestini $P$, Pantelidis $P$, Wells A, Black C, Welsh $K$, Bunn C, Knight C, Foley $P$, du Bois RM: Distribution of novel polymorphisms of the interleukin- 8 and CXC receptor 1 and 2 genes in systemic sclerosis and cryptogenic fibrosing alveolitis. Arthritis Rheum 2000, 43(7):1633-1640.

17. Kim TH, Lee $Y H$, Kim KH, Lee $S H$, Cha JY, Shin EK, Jung S, Jang AS, Park SW Uh ST, Kim YH, Park JS, Sin HG, Youm W, Koh ES, Cho SY, Paik YK, Rhim TY, Park CS: Role of lung apolipoprotein A-I in idiopathic pulmonary fibrosis: antiinflammatory and antifibrotic effect on experimental lung injury and fibrosis. Am J Respir Crit Care Med 2010, 182(5):633-642.

18. Hedrick PW: Gametic disequilibrium measures: proceed with caution. Genetics 1987, 117(2):331-341

19. Stephens M, Smith NJ, Donnelly P: A new statistical method for haplotype reconstruction from population data. Am J Hum Genet 2001, 68(4):978-989.

20. Shin HD, Winkler C, Stephens JC, Bream J, Young H, Goedert JJ, O'Brien TR, Vlahov D, Buchbinder S, Giorgi J, Donfield S, Willoughby A, Smith MW: Genetic restriction of HIV-1 pathogenesis to AIDS by promoter alleles of IL10. Proc Natl Acad Sci USA 2000, 97(26):14467-14472.

21. Menashe I, Rosenberg PS, Chen BE: PGA: power calculator for casecontrol genetic association analyses. BMC Genet 2008, 9:36.
22. Hacking D, Knight JC, Rockett K, Brown H, Frampton J, Kwiatkowski DP, Hull J, Udalova IA: Increased in vivo transcription of an IL-8 haplotype associated with respiratory syncytial virus disease-susceptibility. Genes Immun 2004, 5(4):274-282.

23. Heinzmann A, Ahlert I, Kurz T, Berner R, Deichmann KA: Association study suggests opposite effects of polymorphisms within IL8 on bronchial asthma and respiratory syncytial virus bronchiolitis. J Allergy Clin Immunol 2004, 114(3):671-676

24. Hull J, Thomson A, Kwiatkowski D: Association of respiratory syncytial virus bronchiolitis with the interleukin 8 gene region in UK families. Thorax 2000, 55(12):1023-1027.

25. Ross OA, O'Neill C, Rea IM, Lynch T, Gosal D, Wallace A, Curran MD Middleton D, Gibson JM: Functional promoter region polymorphism of the proinflammatory chemokine IL-8 gene associates with Parkinson's disease in the Irish. Hum Immunol 2004, 65(4):340-346.

26. van der Kuyl AC, Polstra AM, Weverling GJ, Zorgdrager F, van den Burg $R$ Cornelissen M: An IL-8 gene promoter polymorphism is associated with the risk of the development of AIDS-related Kaposi's sarcoma: a casecontrol study. AIDS 2004, 18(8):1206-1208.

27. Lee WP, Tai DI, Lan KH, Li AF, Hsu HC, Lin EJ, Lin YP, Sheu ML, Li CP, Chang FY, Chao Y, Yen SH, Lee SD: The -251T allele of the interleukin-8 promoter is associated with increased risk of gastric carcinoma featuring diffusetype histopathology in Chinese population. Clin Cancer Res 2005, 11(18):6431-6441.

28. Dapas B, Tell G, Scaloni A, Pines A, Ferrara L, Quadrifoglio F, Scaggiante B: Identification of different isoforms of eEF1A in the nuclear fraction of human T-lymphoblastic cancer cell line specifically binding to aptameric cytotoxic GT oligomers. Eur J Biochem 2003, 270(15):3251-3262.

doi:10.1186/1465-9921-12-73

Cite this article as: Ahn et al:: A promoter SNP rs4073T $>A$ in the common allele of the interleukin 8 gene is associated with the development of idiopathic pulmonary fibrosis via the IL-8 protein enhancing mode. Respiratory Research 2011 12:73.

\section{Submit your next manuscript to BioMed Central and take full advantage of:}

- Convenient online submission

- Thorough peer review

- No space constraints or color figure charges

- Immediate publication on acceptance

- Inclusion in PubMed, CAS, Scopus and Google Scholar

- Research which is freely available for redistribution

Submit your manuscript at www.biomedcentral.com/submit
C Biomed Central 